\title{
INVISIBILIDAD Y DESIGUALDAD. LA POLÍTICA ACADÉMICA Y LAS MUJERES DOCENTES EN LA UNIVERSIDAD
}

\author{
Yolanda López Figueroa \\ yolopez@suagm.edu \\ Universidad del Este - Puerto Rico
}

Recibido: 27-02-2016

Aceptado: 02-06-2016

\section{Resumen}

Se analiza la poca representatividad de las mujeres en la academia y las desigualdades que enfrentan para obtener ascensos, mejoras salariales y ascender a puestos altos de poder en las instituciones de enseñanza superior. Contrastan estos hechos con la proliferación de estudios de género en las universidades y la feminización del estudiantado universitario. Se presentan los factores causales más importantes de la política académica como: la cultura laboral universitaria, las estructuras académicas, la doble jornada laboral, los prejuicios y los estilos de administración. Concluye que las universidades no podrán constituirse en agente de cambio social si no modifican sus políticas y estructuras de poder patriarcal que condenan a las docentes a la desigualdad. Concluye proponiendo alternativas para solucionar la problemática.

Palabras Clave: Género, mujeres, educación superior.

\begin{abstract}
This paper analyzes the women's underrepresentation in faculty positions in the universities; the difficulties they have to get tenure-track, salary increases, and the ascension to higher administrative levels. It contrasts these facts with the increase of academics gender studies researchers and the worldwide feminization trend in higher education. The paper introduces experts' findings that assert that they are caused by the departmental climate, academic male structure, the motherhood and domestic responsibilities of women, and management styles. It concludes that the university cannot be considered as a social change agent unless it modifies the patriarchal practices and power structures that perpetuate women's inequality in higher education and presents the most recommended alternatives to solve this problem.
\end{abstract}

Keywords: Gender, women, higher education. 


\section{Introducción}

El reclamo de la igualdad educativa para las mujeres ha sido constante en los discursos occidentales pro igualdad feministas por siglos. El punto medular de esta posición declara que mediante la educación se erradicarían las fronteras y las jerarquizaciones que habían sumido a las mujeres a un plano social secundario. Ya para el siglo XIII la escritora francesa Christine de Pizan argumentó en The book of the City of Ladies, que la falta de educación, no la posesión de cualidades inferiores "innatas", era lo que atrasaba a las mujeres. Razonaba que si "existiera la costumbre de enviar las hijas a las escuelas, tal como se hacía con los hijos y se les enseñara las ciencias naturales, ellas podrían aprender cabalmente y entender las sutilezas de todas las artes y las ciencias tan bien como los hijos". (Anderson y Zinsser, 1998: 343). En España, María de Zayas (1590-1661) arremetió contra la crueldad y tiranía masculinas que mantenían a las mujeres enclaustradas y carentes de educación. Tal como Pizan, Zayas admitió que no era la falta de habilidades sino la carencia de educación lo que impedía a las mujeres el conocimiento:

"En empezando a tener discursos las niñas, pónenlas a bordar y hacer vainicas... Si nos dieran libros y preceptores, fuéramos tan aptas para los puestos y las cátedras como los hombres y quizás más agudas" (Flores y Flores: 1998: 16).

En el siglo XVI, la inglesa Bathsua Makin propuso en An Essay to Revive the Ancient Education of Gentlewomen los beneficios de una educación femenina que estimulara la búsqueda del conocimiento y el ejercicio de la mente. Mary Astell en el 1694 escribió su libro A Serious Proposal to the Ladies con el que trató de que sus contemporáneas tomaran conciencia de las posibilidades inexplotadas que tienen las mujeres por falta de la educación. Llevó a cabo una exhaustiva crítica de los sistemas instruccionales ingleses, particularmente por la ineficiencia contenida en ellos, que de alguna forma empujaba las mujeres a contraer matrimonio con el único propósito de tener un soporte económico "respetable". Consciente de los obstáculos que trae la vida conyugal a la actividad intelectual, la autora aconsejó a las mujeres que deseaban "escapar" de las obligaciones domésticas a unirse en sororidades o “colegios". También afirmo que la educación elevaría a las mujeres a un grado de conciencia que su propia situación la haría mejor contra el abusivo poder masculino (Lerner, 1993: 200206).

Pero quizás el más famoso escrito sobre la igualdad femenina nos llega de Mary Woolstonecraft, considerada una de las propulsoras del feminismo inglés del siglo XVIII. Su libro, Vindicación de los derechos de la mujer, escrito en 1792, es un alegato contra la inferioridad legal y social a las que estuvieron sometidas las mujeres de su tiempo. El mismo parte de la tesis de la necesidad de la igualdad educativa para hombres y mujeres. Su propósito fundamental fue debatir el esencialismo femenino de la época que afirmaba la superioridad del 
hombre debido a su fortaleza física y que siempre vinculaba a las mujeres a los hombres de manera subordinada, sólo como hijas, madres o esposas, pero nunca como iguales. Postulaba finalmente, una nueva educación para conducir a la libertad, no el saber incompleto y vigilado que se admitía para las mujeres.

$\mathrm{Su}$ argumento en pro de la igualdad femenina se fundamenta en una de las premisas ilustradas: la justicia, y escribe:

"La igualdad de la mujer no sólo es justa, sino de manera especial socialmente necesaria para la marcha de la sociedad y de la humanidad, por y para la realización personal de la mujer y del varón [...]”' (Woolstonecraft, 1977: 143).

Al admitir que el origen de la subordinación de la mujer se encuentra en su debilidad física, Woolstonecraft cuestionaba la tendencia cultural de relacionar lo femenino con lo natural. Para ello, traslada el concepto de naturaleza a la razón. Por consiguiente, la preeminencia masculina sería injustificada, pues tanto las mujeres como los hombres poseen razón, y a medida que la civilización progresa, la razón avanza. Ya que las mujeres habían tenido hasta ese momento una instrucción repetitiva que las alejaba de la razón, se encontraban en un estado antinatural. Así, la difusión de la razón, por medio de la educación y la reforma de los esquemas pedagógicos las llevarán a la realización de su racionalidad innata (Evans, 1980: 13).

A la luz de estos planteamientos se podría pensar que las mujeres nos encontramos al borde de obtener la igualdad cuando constatamos el vertiginoso acceso femenino en las instituciones de enseñanza superior. No solo eso, desde las últimas décadas del siglo XX las mujeres son, en la gran mayoría de los países occidentales la mayoría de las inscritas y egresadas. Además, las universidades se han convertido en las principales gestoras de estudios feministas, sobre las mujeres y de investigaciones que incorporan la perspectiva de género para explicar la situación de desigualdad y discriminación.

Visto desde el exterior, se pensaría que las universidades han logrado derribar las fronteras de la discriminación y desigualdad femenina. Pero ¿cuál es la situación y a qué problemáticas se enfrenta el grupo de mujeres que laboran como docentes universidades? ¿Podemos afirmar que la feminización de la matrícula universitaria y el desarrollo de los estudios de la mujer y de género han incidido en una mejora de las condiciones laborales de las mujeres que trabajan en las universidades? Para contestar esas preguntas este ensayo recoge las aportaciones que la literatura con perspectiva de género propone para examinar la realidad laboral de las académicas abordando tanto aspectos de la cultura de género como de la cultura organizacional universitaria que inciden en la situación de invisibilidad y desigualdad salarial y de poder de este grupo laboral.

A modo de conclusión, se reflexiona sobre las tareas más urgentes que se deben realizar para detener la desigualdad y propiciar cambios sustanciales que redunden en la equidad. 


\section{Las mujeres y la universidad}

Desde sus inicios la universidad se ha caracterizado por conciliar tanto el conocimiento teórico, como el fomentado en las escuelas catedralicias medievales, donde predominaba el estudio de las artes liberales, como el conocimiento práctico favorecido en las universitas o gremios de artesanos que estuvieron íntimamente relacionados al renacer del comercio y de las ciudades de la Europa Central. Los estudios y métodos de enseñanza no estaban claramente estructurados y dependían de cada maestro (Jiménez Vargas, n.d.: 3-4) y buscaban resolver, como las de hoy día, problemáticas de su momento.

En la actualidad ese ideal funcionalista de la educación universitaria se ha compaginado con uno filosófico encaminado a la búsqueda de conocimiento, la autonomía y el libre intercambio de ideas como el fin último. Así, se considera la educación superior como derecho humano y un bien político social y que las universidades, junto con los Estado y la sociedad, tienen la obligación de definir los principios básicos en los cuales se fundamenta la formación ciudadana. Las exigencias sociales llevan a organizaciones internacionales, como la Organización de Estados Iberoamericanos (OEI), a demandar una educación superior que sea:

"[E]lemento insustituible para el avance social, la generación de riqueza, el fortalecimiento de las identidades culturales, la cohesión social, la lucha contra la pobreza, la prevención del cambio climático y la crisis energética, así como para la promoción de una cultura de paz" (OEI, s.f.).

Las universidades occidentales fueron instituciones concebidas desde sus orígenes como espacios exclusivamente masculinos, según lo expresa el siguiente decreto de la Universidad de Bolonia del 1377:

"Ya que la mujer es la razón primera del pecado, el arma del demonio, la causa de la expulsión del hombre del paraíso y de la destrucción de la antigua ley, y ya que en consecuencia hay que evitar todo comercio con ella, defendemos y prohibimos expresamente que cualquiera se permita introducir una mujer, cualquiera que ella sea, aunque sea la más honesta en esta universidad" (Palermo, 2006: 377).

Sin embargo fue precisamente en Italia, luego de finalizada la Edad Media, donde un puñado de mujeres de la aristocracia pudo ingresar a universidades y obtener títulos de doctoras y hasta ejercer como docentes.

El siglo XVIII se considera el siglo pedagógico por excelencia; durante el cual "la educación ocupó el primer plano de las preocupaciones de los reyes, pensadores y políticos” (Luzuriaga, 1989: 37). La gran mayoría de los filósofos ilustrados valoraron la educación y la 
consideraron como el único vehículo capaz de crear un nuevo "hombre" despojado de los viejos prejuicios religiosos. No deja de ser cierto que el proceso originado habría de tener efectos irreversibles, pero el esquema educativo que muchos centros de instrucción, tanto religiosos como laicos, reconocía que lo necesario para las niñas era el dominio de destrezas básicas como la lectura, la escritura y la aritmética y la función social de exclusividad doméstico-familiar que estas niñas habrían de llevar a cabo estuvo lejos de ser cuestionada. El saber transmitido a las niñas fue uno incompleto y totalmente vigilado, en el cual su experiencia educativa estuvo fuertemente marcado por el papel de madre y esposa, que se suponía sería el fin ulterior de toda mujer, sin importar su condición social (Sonet, 1991: 130-132). Un ejemplo claro de esa educación diferenciada lo encontramos en el tratado de Juan Jacobo Rousseau, conocido como Emilio o de la educación, obra escrita en el 1756, que orientó gran parte de la pedagogía moderna.

Las ideas de Rousseau sobre el estado de la naturaleza en el hombre, en armonía con su mundo físico, tuvieron grandes repercusiones dentro de la ideología liberal de su tiempo. Rousseau es considerado por muchos como el más influyente intelectual moderno. Aunque Voltaire había comenzado con las consignas de lo que luego se conoció como modernidad, la entronización de la razón y la ruptura con el orden teológico, Rousseau fue el primero en combinar todas sus destacadas características dentro del proyecto moderno ilustrado. Afirmó su derecho a rechazar el orden existente en su totalidad, confió en su capacidad para rehacerlo desde los cimientos, de acuerdo con principios ideados por él mismo. Tuvo además, la creencia de que esto podía lograrse por medio del proceso político y no por el reconocimiento del papel que el instinto y la intuición desempeñan en la conducta humana (Johnson, 1990: 14). Sus trabajos: Emilio o de la educación, Discurso sobre el origen y los fundamentos de la desigualdad entre los hombres (1755) y El contrato social (1762) pueden clasificarse como una literatura militante al servicio de la burguesía. Cada libro desarrolla la experiencia individual, social y política necesaria para resistir el mal de su tiempo. Mediante el Discurso y El contrato social, Rousseau preparó teórica y políticamente el camino de la revolución. La efervescencia revolucionaria de entonces exigió la construcción de todo un aparato de consentimiento social que asegurase la hegemonía de esa pujante clase frente a la monarquía, más que una toma real de poder político o una transformación económica.

En el Emilio, Rousseau denunció igualmente el mal por el cual atrasaba el hombre moderno y la sociedad civilizada en general. Todo el progreso de su época, con sus leyes y su cientificismo, sólo habían logrado extender el vacío, la esclavitud y la discordia entre los hombres. De igual forma le concede, por primera vez, plena personalidad a la niñez y establece que la tarea educativa sea integral. El nuevo concepto de la labor educativa que propuso estuvo acorde con la necesidad de transmitir una verdadera praxis: reflexión y acción del ser humano sobre el mundo para así poder transformarlo. En esta práctica se opondría el sentimiento y la sensibilidad a la autoridad y a las costumbres, ideario que refleja tanto el optimismo antropológico como su pesimismo histórico. En el libro V de Emilio se nos presenta a Sofía o El 
tratado para la educación de la mujer, donde se encuentran anotadas una serie de concepciones hombre y mujer, que reflejan las características de la cultura interna del estado que Rousseau deseaba promover.

La Sofía de Rousseau nos aparece como un nuevo producto cultural de mujer. Ella es la perfecta compañera para Emilio, nuevo hombre burgués rousseauniano que llevará a cabo su proyecto político. De entrada se explicita que por sus diferentes naturalezas, la educación del hombre y la mujer debe variar y así:

"Siguiendo las direcciones de la Naturaleza, deben obrar acordes, pero no deben hacer las mismas cosas; el fin de sus tareas es común, mas éstas son diferentes, y por consiguiente, los gustos las dirigen" (Rousseau, 1989: 238).

Por esa misma "naturaleza", el hombre debe ser activo y fuerte y la mujer débil y pasiva. El fin de esa pasividad femenina era agradar al hombre porque: "el mérito del varón consiste en un poder, y sólo por ser fuerte agrada” (Rousseau, 1989: 279). El filósofo francés no niega el poder a las mujeres, pero sólo el poder que tiene el débil frente al opresor, "el ser objeto de poder del otro en el cual el dominado confiere por su sujeción, poder y existencia al dominador" (Lagarde, 1990: 142). Al no haber paridad alguna entre ambos, sus campos de acción deben ser diferentes. A la mujer le pertenece el imperio de lo privado donde debe llevar una vida sedentaria, educándose para su exclusiva labor: la maternidad y más tarde ser quien mantenga unida a la familia. Ya que la naturaleza "le fio el depósito de los hijos", así la infidelidad es más castigable, pues, "disuelve la familia y quebranta todos los vínculos, dando al hombre hijos que de él no son" (1989: 281). En un orden capitalista-patriarcal, donde prevalecía la ley de la herencia, el hombre tenía que estar absolutamente seguro de dejar sus propiedades y capital a herederos legítimos. No es gratuito entonces que el pedagogo hiciera tanto énfasis en el control del cuerpo de la mujer.

El ideal rousseauniano exigía a la mujer un barniz intelectual que la capacitara para ser la compañera ideal; capaz de sostener una conversación agradable, pero que no tuviera un excesivo conocimiento que apocara al hombre. Su educación debía estar dirigida al buen mantenimiento del hogar, a la crianza de los hijos, pero sobre todo, a que comprendiera cuál era su posición frente al hombre. Por ello, sus virtudes debían desarrollarse con cierto recelo, teniendo siempre en mente las diferencias físicas y morales que la naturaleza confería a mujeres y a hombres. Este proceso de diferenciación tan marcado pudo haber contribuido al desarrollo de un debate sobre las posibilidades de las mujeres para acceder a las universidades y para ejercer carreras consideradas como masculinas. Se citan casos de mujeres que recurrieron a estrategias que iban desde el uso de nombres masculinos hasta el travestimos para poder asistir a las universidades y posteriormente practicar sus carreras (Palermo, 2006: 879-380).

No es hasta el siglo XIX cuando se comienzan a ver cambios importantes respecto a la incorporación de mujeres a nivel universitario. En Estados Unidos, por ejemplo, se creó en el 
1837 el Oberling College, primera universidad que formalmente aceptó mujeres en sus planteles. Posteriormente se fundaron las llamadas Seven Sisters (Bernard, Bryn, Mawr, Mount Holyoke, Radcliffe, Smitt, Vassar y Wellesley), centros de enseñanza superior de matrícula exclusivamente femenina que, a diferencia del Oberling College, poseían el mismo currículo de las universidades Ivy League, a las que se sólo asistían hombres. Al poco tiempo otras universidades privadas y estatales estadounidenses aceptaron mujeres, particularmente en las carreras relacionadas con la medicina. Durante el mismo periodo algunas universidades europeas en Francia, Alemania y en Rusia comenzaron a permitirles ingreso, también en facultades de medicina. Las universidades inglesas hicieron lo propio en las postrimerías del siglo, luego superar la oposición de los sectores más conservadores.

En España las regulaciones de los proyectos de instrucción aprobados al iniciarse la segunda mitad del siglo beneficiarían de entrada, como señala Flecha García, a los sectores burgueses masculinos “... pues no era imaginable el que las mujeres estuvieran llamadas a las funciones y a las iniciativas descritas en los diferentes textos legales de la época" (1998:160). Sin embargo, peticiones particulares, más no legislaciones, abrieron la puerta para que un puñado de mujeres pudiesen optar por una educación en los institutos de segunda enseñanza como un espacio alternativo al de las escuelas normales. De forma lenta pero constante, desde 1870 hasta 1882, aumentó tanto el número institutos como el de jóvenes inscritas en ellos. Ya para la segunda etapa, comprendida entre los años de 1882 a 1900, se percibe un aumento significativo en el número de matriculadas y de centros educativos respecto al periodo anterior (Flecha Garcia, 1998: 166: 174).

Las pocas mujeres españolas que lograron acceso a educación superior en el siglo XIX debían contar con la aprobación de la Dirección General de Instrucción Pública, que estudiaba cada caso de manera individual (Palermo, 2006: 382-392). Fue durante la década de 1870 cuando la facultad de medicina de la Universidad de Barcelona permitió el ingreso de varias alumnas en sus aulas y en el 1882 Dolores Aleu Rivera y Martina Castells Ballespí, ambas egresadas de esa facultad, defendieron su tesis doctoral en la Universidad Central de Madrid, la única institución que para entonces otorgaba el grado (Flecha García, 1999: 242-244). A diferencia de sus contrapartes masculinos, las universitarias estuvieron sometidas a tratos diferenciados como la necesidad de autorizaciones especiales para ser consideradas como alumnas oficiales, ir acompañadas y sentarse en lugares especiales al lado del profesor. No fue hasta la aprobación de la Real Orden de 8 de marzo de 1910 que se les autorizó el acceso oficial universidades españolas (Guil Bozal y Flecha García, 2015: 128). El panorama tomó un rumbo diferente desde la década de 1980 cuando el número de universitarias españolas superó al de los hombres; para el año académico de 2011 ya constituían el 54\% de la matrícula y el 58,6\% de las tasa de graduación (Guil Bozal y Flecha García, 2015: 138).

Por otro lado, en América Latina las universidades surgieron para el siglo XVI durante el periodo colonial, pero no fue hasta el siglo XIX cuando en Brasil, México, Chile, Cuba y Argentina incorporaron estudiantes mujeres en sus aulas. La situación cambia a lo largo del 
siglo XX y se caracteriza por el acceso sistemático e ininterrumpido de las mujeres a los centros universitarios (Izquierdo, 2009, Cerros Rodríguez y Ramos Tovar, 2009, Miranda Guerrero, 2007, Correa Olarte, 2005). Ya en el presente siglo se habla del fenómeno de la feminización de la educación superior evidenciado por el hecho de que más de la mitad de número de los egresados de las universidades latinoamericanas son mujeres (Jiménez Gonzáles y Laurier, 2012: 788). En el caso de Puerto Rico cerca del 60\% de la matrícula en las universidades públicas y privadas del 2010 eran mujeres. En esta isla la distribución de matrícula universitaria se ha mantenido estable a un promedio de $40 \%$ para el género masculino y $60 \%$ para el femenino entre años 2001 al 2010 (Gobierno de Puerto Rico, 2011: 8).

Como producto del aumento al acceso educativo universitario se ha visto un alza en las oportunidades de empleo para las mujeres latinoamericanas, a un ritmo superior que las oportunidades para los hombres. Así, la ocupación laboral femenina en América Latina ha presentado una tasa de crecimiento anual de $4.43 \%$ en tanto que la masculina han incrementado en un $2.94 \%$. Pero, a pesar de ese adelanto y del desempeño exitoso de las egresadas, el acceso femenino a puestos de alto rango o de liderazgo se ha estancado (Ledwith y Manfredi, 2000: 8). La UNESCO (2013: 100-101) señala que el tipo de carreras que eligen las universitarias de las regiones de Latinoamérica y el Caribe siguen siendo las de menor compensación salarial particularmente en un mercado de trabajo que además tiende a pagar menos a las mujeres a igual calificación que los hombres. Por un lado, se plantea que ello puede deberse a una llamada extensión de los roles de género que "normaliza" la percepción de las carreras para mujeres con roles conocidos en los hogares, la escasez de modelos femeninos en profesiones como las matemáticas y la ingeniería (muchas veces vistos como poco femeninos) y prácticas docentes "adversas y poco favorables para integrar en el contexto escolar las potencialidades diferenciadas de ambos sexos. También se señala que factores de género relacionados con las funciones domésticas y de cuidado obligan a muchas mujeres a aceptar trabajos con salarios bajos, renunciar a empleos o ascensos por tener hijos o personas dependientes a su cuidado (Guil Bozal, 2007: 20-22).

\section{La situación de las docentes universitarias}

La ausencia de las mujeres en la academia constituye un problema mundial, según comprueban las estadísticas. Entre 1977 a 1988 la proporción de mujeres desempeñándose como profesoras y profesoras asociadas en Australia aumentó en $2.8 \%$, la de lectoras en $6.7 \%$ (Bacchi, 1993: 40). Aunque su porciento aumentó para el 2014, todavía constituían el 43.6\% en las plazas de facultad, como lectoras, y sólo el $29.9 \%$ ostentaban alguna posición sobre el rango de lectoras. (Australian Goverment, 2015). En términos salariales, un estudio llevado a cabo en 
la Universidad de Western Australia reveló la existencia de una brecha salarial de un $15 \%$ entre facultad masculina y femenina (Currie y Hill, 2013).

Durante la década de 1990 Finlandia, que contaba con un nivel de participación laboral femenino de $50 \%$, las mujeres sólo ocupaban el $13 \%$ de puestos con rango de profesora y $22 \%$ como profesoras asociadas. En Suecia la proporción era de 9\% para el 1996 y en los Países Bajos solo el 5\% (Ledwith y Manfredi, 2000: 8-9). Más recientemente, el Global Gender Index reportó que para el 2013 en Dinamarca las mujeres académicas constituían 31.0\%, en Noruega el 31.7\% y en el 36.7\% en Suecia (Grove, 2013: s.p.). En México, el porcentaje de mujeres en puestos docentes aumentó de un $17 \%$ en 1969, a 50\% en 2000 (Cerros Rodríguez y Ramos Tovar, 2009: 188). En términos proporcionales, según las cifras del Sistema Nacional de Investigadores (SNI), las mujeres registradas como "investigadoras nacionales" aumentó de 21\% en 1991 a un 33\% en 2011 (Ávila, 2015: 35).

Según el Instituto de formación del profesorado de España, para los años 2006-2007, el $36 \%$ del personal docente de las universidades públicas eran mujeres y aquellas con rangos de catedráticas representaban sólo el 14\% (Tomàs, Ion y Bernabue, 2013: 19). Si el hecho de constituir una minoría en el mundo académico es preocupante, más aun es constatar que la mayoría de las cátedras y los puestos de mayor sueldo y prestigio son ocupados por hombres (Guil Bozal, 2007: 95). Aunque, como señalan más recientemente Guil Bozal y Flecha García (2015:139-141), se ha triplicado el número del profesorado, el aumento no ha dado paso a la paridad y el número de profesoras no supera el $38.7 \%$.

El problema de la poca representatividad femenina en la academia ha generado un análisis que busca explicar sus causas, y sobre todo, proponer estrategias para la solución. Desde la perspectiva de género los sistemas educativos son considerados como aparatos ideológicos que contribuyen a la adquisición y transmisión de roles de género, entendiéndose el género como: "La red de creencias, rasgos de personalidad, actitudes, sentimientos, valores, conductas, y actividades que diferencian al hombre de la mujer mediante un proceso de construcción social que tiene una serie de aspectos distintivos" (Benería y Roldan, 1992: 24).

Las universidades en particular son vistas como espacios en los que se mantienen relaciones de dominación mediante sistemas y modelos sociales hegemónicos en los que imperan nexos jerárquicos y de exclusión donde la influencia de lo masculino corre a través del currículo, tanto en las metodologías como en los temas seleccionados y en el lenguaje utilizado (Acuña Rodríguez, 2014: 91). Al igual que en muchas otras profesiones dominadas por hombres, "lo femenino" se continúa definiendo en el mundo académico a través del crisol del mito cultural de la separación de espacios limitando la capacidad de las mujeres para poder integrar con éxito el trabajo y la familia. Este hecho se potencializa más aún cuando se espera que los y las docentes que dediquen sus vidas a la búsqueda del conocimiento, la excelencia académica, el logro de metas y la eficiencia lo que deja poco tiempo para realizar otras tareas (Aluko, 2009: 2100). 
Irónicamente, a pesar de que fue en el ámbito académico donde nació el concepto y perspectiva de género y donde se generan la mayor parte de las investigaciones feministas y que utilizan esa perspectiva, las instituciones de enseñanza superior no han necesariamente acogido la temática para desarrollar cambios en su interior (Buquet Corletto, 2011:211) lo que puede explicar las situación desigual y discriminatoria que se sigue observando en esos espacios laborales. En un estudio en una universidad española, Billarín Domingo (2013: 91-104) encontró que existe desconocimiento en la gran mayoría del profesorado entrevistado sobre las aportaciones que los estudios feministas sobre mujeres y los de género, lo que en cierta medida puede explicar la renuencia a tratar temas de estudios de género en las asignaturas resistencias y prejuicios. En su estudio instrumental encontró además, que parte la facultad consideraba que las aportaciones de los estudios sobre las mujeres y de género eran "cuestiones de actitudes y valores' y no de conocimiento científico y que se entendía que la igualdad entre hombres y mujeres era un asunto ya resuelto. Expone la autora que existió la idea en otros(as), entrevistados(as) de que no es necesario una preparación particular para incorporar los temas de igualdad hombre-mujer y no discriminación y que por ello no justifica que existan materias específicas sobre el tema.

Por otro lado, según reporta Forster (2001: 28), hay más concentración de mujeres en disciplinas de las Ciencias Sociales pero muy pocas en las Ciencias Naturales; su cantidad es más alta en un pequeño grupo de disciplinas como enfermería, psicología, leyes, lenguas, educación y las humanidades y muy poco representadas en las ciencias, matemáticas, ingeniería y computación. A su vez, hay más mujeres en puestos bajos de investigación y como reciben menos ascensos que los hombres, sus sueldos son más bajos que los de sus colegas. En el Reino Unido dos terceras partes de la plantilla que trabaja a tiempo parcial ofreciendo cursos son mujeres (Ledwith y Manfredi, 2000: 10).

En Estados Unidos, existen más mujeres en plazas sin derecho a permanencia (non tenure) ofreciendo cargas completas a nivel sub-graduado frente a sus compañeros que generalmente tienen más cursos a nivel graduado o se encuentran en puestos de investigación o administración (Gasser y Shaffer, 2014: 335). La Asociación Americana de Profesores Universitarios (conocida como la AAUP, por sus siglas en inglés) señala que para el 2014 había más mujeres en cargos académicos de bajo rango que sus colegas hombres. El tener poca presencia en puestos administrativos puede estar asociado a la cantidad de tiempo y trabajo que invierten en labores de docencia, mentoría y de servicio, junto con una aparente renuencia a declinar trabajos en proyectos de investigación, lo que a la larga entorpece el ascenso a puestos más altos de poder en las instituciones (Kimbal et al., 2001 en Gasser y Shaffer, 2014: 338). Su concentración en la docencia tiene también un efecto negativo en las posibilidades de poder obtener permanencias pues, se sigue considerando la labor de investigación, sobre otras, como primordial a la hora de obtener un ascenso, aumento o un puesto permanente.

Acker y Armenti (2004: 3-4) señalan que para explicar este hecho se debe tomar en consideración primero, la naturaleza de las estructuras académicas y su cultura laboral. Uno de 
los principios fundamentales del trabajo académico es el concepto del mérito, en el cual las y los académicos y académicas son evaluados y evaluadas por su desempeño y en el cual las diferencias en la capacidad para ese desempeño son descartadas sobre las bases de la "justicia". El trabajo académico universitario de hoy día implica una diversidad de funciones que van más allá de la docencia, lo que conlleva un sinnúmero de actividades como la investigación, publicación y presentaciones en congresos internacionales o nacionales. Los sistemas de evaluación están centrados en medir la excelencia y requieren evidencia de aspectos relacionados con la docencia, el peritaje en el área de especialidad, el dominio y la utilización de las nuevas estrategias de enseñanza, la investigación o el trabajo creativo, el uso de la tecnología y los programados para la enseñanza a distancia y el servicio a la institución. No olvidemos el nuevo rol de consejeros o tutores estudiantiles que hoy día tienen los y las docentes "que se define como académica, pero que termina por incidir en aspectos de índole personal, sin tener la formación y condiciones para el desempeño de este nuevo papel" (Chaves Gutiérrez, Chaves Gutiérrez y Ramírez Díaz, 2009: 259). Muchas universidades dependen de esta labor para poder lograr altas cuotas de retención y graduación. Así, la estancia en la institución, el tipo de nombramiento, el sueldo y el rango académico dependerán de mantener altos estándares en todas esas labores.

Estudios que miden el impacto del trabajo académico en la salud concluyen que tanto hombres como mujeres que laboran en el campo académico padecen un sinnúmero de afecciones físicas y mentales que van desde las migraña, trastorno del sueño hasta el estrés, ansiedad y depresión y que son consecuencia de aspectos estructurales como los cambios en la contratación y métodos de evaluación, hasta institucionales de los cuales resaltan la inadecuada, las políticas institucionales, el clima laboral y las relaciones sociales ocurridas en el espacio laboral (Ramos Tovar, 2012: 281).

\subsection{La doble jornada}

Para la gran mayoría de académicas la situación es más compleja porque deben conciliar esta faceta laboral tan demandante con las tareas de cuidado y maternales, la llamada jornada doméstico-maternal, "que no es concebida social y culturalmente como trabajo, sino como actividad propia del sexo femenino" (Lagarde, 1990: 114) por el hecho biológico de la maternidad.

"[S]e trata de dos trabajos diferentes pero realizados cada día... la jornada pública de trabajo productivo, asalariado, a contrato, y la jornada privada de trabajo reproductivo... [L]a jornada pública se lleva a cabo [...] en un lugar destinado a la producción [...] y la jornada reproductiva es doméstica, se lleva a cabo en la casa" (Lagarde, 1990: 111-112). 
Durán Herás (2012: 40-41) lo describe como el tipo de trabajo que envuelve labores domésticas (de limpieza), de cuidado de hijos e hijas, de educación y/o recreo, de preparación de alimentos, y de cuidado de enfermos(as) y/o de personas envejecientes. Se clasifica como trabajo no remunerado, que sería mejor llamarlo trabajo no monetarizado "para destacar que es un tipo de trabajo que no da lugar a transacciones monetarias inmediatas" realizado a nivel mundial por mujeres por ser parte de la tradicional división sexual del trabajo y contribuye a reducir la posibilidad de que puedan incorporarse a un trabajo remunerado:

"El trabajo no remunerado en los hogares se ha interpretado tradicionalmente como una obligación a la que el sujeto ha de someterse en función de su pertenencia a un colectivo socialmente construido sobre criterios de sexo... En el implícito contrato social que regula la división del trabajo entre hombres y mujeres también hay "obligaciones propias de su sexo" que recaen principalmente sobre los varones, como la defensa física y la provisión de recursos económicos. Mientras unos y otras aceptaron la división sexual del trabajo como natural, solo generó conflictos menores; su eficacia se ha reforzado con todos los recursos que una sociedad es capaz de generar, como la educación, las leyes, la ética y la estética” (Durán Herás, 2012: 205).

El trabajo no remunerado en el hogar tiene efectos contraproducentes en el ámbito laboral remunerado ya que le resta tiempo y energías a una tarea altamente demandante como el de la academia. Acker y Armenti encontraron que las académicas madres que participaron en sus dos estudios planteaban que habían padecido de altos niveles de ansiedad, estrés, cansancio y falta de sueño como problemas asociados a la combinación del trabajo académico con el doméstico y el de crianza. Hubo madres que declararon haber mantenido en secreto su embarazo, planificar partos durante los meses de vacaciones o definitivamente no tomar las licencias por maternidad por temor a que ello afectara sus carreras. Las solteras, por otro lado, pensaban seriamente en casarse o tener hijos por el efecto negativo que podría tener para alcanzar una plaza permanente. Ser madre en la academia es tabú, un asunto del que no se habla porque podría significar, ante los colegas hombre, la posibilidad de no poder lidiar con las exigencias profesionales. No es sorprendente entonces, el hecho de que en Estados Unidos el $44 \%$ de las mujeres con plazas permanentes son madres y esposas frente al 70\% de los hombres en los mismos puestos (Manson, 2013). Aun así, muchas tratan de mantener altos estándares en el trabajo académico mientras crían sus hijos e hijas utilizando como estrategia el trabajar más arduamente y por más tiempo. Acker y Armenti (2004: 11-12) sospechan que este fenómeno se debe a la intensificación y el aumento de las expectativas inherentes en el trabajo académico, especialmente en las universidades de hoy día tan orientadas a la investigación.

Conciliar trabajo académico con el doméstico-familiar retrasa las carreras de mujeres en ciertos momentos de su vida, particularmente cuando tienen hijos e hijas pequeños(as) y puede resultar en poca producción académica y escasa promoción laboral pero cuando crecen sus hijos 
o hijas, los patrones laborales se regularizan y se incrementa su productividad (Ramos Tovar, 2012: 284). Cerros Rodríguez y Ramos Tovar (2009: 193) señalan que la mayoría de los estudios sobre la doble jornada en las académicas presentan dos posiciones encontradas: una que se caracteriza por esta situación genera estrés, inseguridad y sentimiento de culpa, frente a sentimientos de emociones de plenitud, orgullo y satisfacción. Estos hallazgos confirman la afirmación de Lagarde (1990: 126-127) de que la mayoría de las mujeres trabajadoras viven en un estado contradictorio opresivo-liberador en el cual el conflicto es explicado y vivido tanto con angustia como con incapacidad, disgusto o culpa. Es importante apuntar que el impacto emocional que la doble jornada tiene en la salud física y emocional de las docentes, depende del grado de aceptación del rol de madre-esposa por parte de la mujer, como también por las redes de apoyo (pareja, formales o informales), con las que pueda contar para poder lidiar con la doble carga. Igualmente cierto es que tanto mujeres como hombres sienten que el trabajo académico afecta el tiempo dedicado a sus hijos, la relación con su pareja, disminuye o cancela la cantidad de tiempo de ocio con la familia y potencia la sensación de no poder conciliar trabajo y familia (Ramos Tovar, 2012: 296-297).

\subsection{Prejuicios y estilos de trabajos administrativo}

Otro factor que interviene lo sería el estilo o clima de trabajo dentro de las universidades que se caracteriza por la designación de mujeres para trabajar en comités de poca importancia y las prácticas administrativas que sabotean los intentos de ascensos de ellas con pobres recomendaciones o sugiriendo que no están preparadas para el desempeño. Se reportan además, otras conductas discriminatorias como el acoso sexual, el uso de lenguaje sexista y sarcasmos, levantar la voz, los chistes discriminatorios, insultos velados o la condescendencia (Ledwith y Manfredi, 2000: 13). Persiste también un doble discurso que acepta como bueno en los hombres la alta eficiencia, competitividad y los estilos que rayan en la agresividad y mientras que en las mujeres estas conductas se consideran como ambiciosas o "poco femeninas" Factores como el pertenecer a minorías étnicas, la orientación sexual o la edad también contribuyen a la invisibilidad o el retrasar el éxito académico. La combinación de estos factores tiende a aumentar la edad en que se alcanza el mayor desarrollo laboral, así que mientras los hombres llegan al pico de la producción académica entre los 45 a 49 años, las mujeres lo hacen 5 años más tarde (Ledwith y Manfredi, 2000: 14).

Por otra parte, muy pocas académicas endosan el análisis y la perspectiva de género, hacen del feminismo una opción política o peor aún, apoyan los derechos de las mujeres en su trabajo. La marginación del feminismo se sigue evidenciando por la dificultad que persiste en muchas instituciones para aceptar los estudios de género o la perspectiva de género como un enfoque valido en la investigación. El ser feminista continúa viéndose en algunas instituciones como algo raro y muchas académicas feministas señalan haber sido discriminadas o marginadas en sus centros educativos. 
El hecho de ser una mujer educada no implica que favorezca los asuntos de las mujeres ni que reconozcan las desigualdades de género. El que haya algunas mujeres en puestos de poder no garantiza tampoco un cambio en la cultura discriminatoria ya que muchas de ellas emulan el modelo masculino de poder en la profesión, no quieren identificarse con los asuntos de las mujeres por temor a ser consideradas como parcializadas o sencillamente no ha habido en ellas un despertar en la conciencia que las lleve a reconocer que la desigualdad entre los género corre a través de todas las ámbitos de la cultura.

\section{Consideraciones finales}

Para que la universidades del siglo XXI se conviertan en instituciones capaces de desarrollar ciudadanos y ciudadanos que contribuyan al avance social, la generación de riquezas, el fortalecimiento de las identidades culturales y la cohesión social, según lo exige la Organización de Estados Iberoamericanos, deben comenzar por re-examinarse desde su interior e incorporar la perspectiva de género para garantizar la equidad de todo su personal, incluyendo las mujeres académicas. No es posible que se auto-denominen como agentes de cambio económico-social y continúen a la vez reproduciendo estructuras de poder, discursos y prácticas patriarcales.

Es imperativo romper el silencio y admitir que, aunque se han dado cambios importantes, todavía falta mucho por hacer con respecto a la situación de las mujeres docentes al interior de sus instituciones. Se requieren estudios que determinen cómo las presiones de la vida académica inciden sobre la vida de las académicas desde sus múltiples experiencias y subjetividades. Las mujeres académicas debemos acabar con el aislamiento tan propio de la profesión creando grupos de discusión, redes de apoyo y siendo mentoras para las que recién entran a la profesión.

Es preciso, además, desarrollar estrategias para elegir mujeres comprometidas que nos represente en los organismos institucionales universitarios y crear un caucus femenino que se constituya en un frente unido ante las autoridades para exigir que se revisen las cargas docentes, se acabe con la discriminación, se reconozca el impacto de la doble jornada en la labor académica y se otorguen más oportunidades para la investigación. Por último, es imprescindible hacer todo lo posible para que se reconozca como válido y se incorpore la perspectiva de género en el currículo, en la capacitación de docentes de todas las áreas académicas y en la legislación universitaria como una forma de promover cambios que vayan encaminados a crear y garantizar la equidad. 


\section{BIBLIOGRAFÍA}

- Acker, Sandra y Armenti, Carmen (2004): "Sleepless in academia". En: Gender and Education, vol. 6, no. 1, pp. 3-24.

- Acuña-Rodríguez, María del Carmen (2014): "Reflexiones en torno al vínculo géneroeducación superior”. En: Educación, (Costa Rica), vol. 38, n. 2, pp. 89-106.

- Aluko, Yetunde Adebunmi (2009): "Work-Family Conflict and Coping Strategies Adopted by Women in Academia". En: Gender \& Behaviour, vol. 7, nº. 1, pp. 2096-2124, [en línea] Disponible en:

http://ip-50-63-24225.ip.secureserver.net:2048/login?url=http://search.proquest.com/docview/219532773?accoun tid=12640 [22/05/2016].

- American Association of University Professors (2014): "List of Tables and Figures for 2013-14 Annual Report on the Economic Status of the Profession”, [en línea] Disponible en: https://www.aaup.org/list-tables-and-figures-2013-14-annual-report-economic-status-profession [27/05/2016].

- Anderson, Ronnie S. y Zinsser, Judith P. (1998): A History of Their Own. Women in Europe, vol. II, New York: Harper \& Row.

- Ávila, María (2015): "La desigualdad de género en la academia mexicana, Más ciencia por México”, [en línea] Disponible en: http://masciencia.org/blog/la-desilgualdad-de-genero-en-laacademia-mexicana [27/10/2015].

- Australian Goverment, Department of Education and Training. (2015): Selected Higher

Education Statistics - 2014 Staff Data, [en línea] Disponible en:

https://www.education.gov.au/selected-higher-education-statistics-2014-staff-data [26/05/2016].

- Bacchi, Carol (1993): "The Brick Wall: Why so Few Women Become Senior Academics", [en línea] Disponible en: http://files.eric.ed.gov/fulltext/EJ472893.pdf [20/08/2015].

- Benería Lourdes y Martha Roldán. (1992): Las encrucijadas de clase y género, México: Fondo de Cultura Económica.

- Billarín Domingo, Pilar (2013): "Docencia universitaria y conocimientos en torno al género. Creencias y prejuicios". En: Cuestiones de género. De la igualdad a la diferencia. №. 8, pp.89106.

- Buquet Corleto, Ana G.; Cooper, Jennifer A. y Rodríguez Laredo, Hilda (2010): Sistemas de indicadores para la equidad de género en instituciones de educación superior. México: UNAM.

- Buquet Corleto, Ana Gabriela (2011): “Transversalización de la perspectiva de género en la educación superior. Problemas conceptuales y prácticos”. En: Perfiles Educativos, nº 32, pp. 211-225. 
- Cerros Rodríguez Elisa y Ramos Tovar, María Elena (2009): "Discurso de género y emociones en mujeres académicas de alto rendimiento". En: Revista Perspectivas Sociales, vol. $11, \mathrm{n}^{\mathrm{o}} .1-2$, pp. 187-129.

- Correa Olarte, María Eugenia (2005): La feminización de la educación superior y las implicaciones en el mercado laboral y los centros de decisión política. Colombia: Universidad Externado de Colombia.

- Currie, Jan y Hill, Beverley (2013): “Gendered Universities and the Wage Gap: Case Study of a Pay Equity Audit in an Australian University". En: Higher Education Policy, n. 26, pp. 6582, [en línea] Disponible en: http://www.palgravejournals.com/hep/journal/v26/n1/full/hep201219a.html [23/05/2016].

- Chaves Gutiérrez, María Antonia; Chávez Gutiérrez, María Rita y Ramírez Diez, Erika (2009): Género y trabajo en las universidades. México: Universidad de Guadalajara.

- Durán Herás, María Ángeles (2012): El trabajo no remunerado en la economía global. España: Rubes.

- Evans, Richard J. (1980): Las feministas, Madrid: Siglo XXI.

- Flecha García, Consuelo (1998): "La incorporación de las mujeres a los Institutos de Segunda Enseñanza en España”. En: Historia de la Educación, Salamanca, vol. 17, pp. 159178, [en línea] Disponible en: http://revistas.usal.es/index.php/0212-0267/article/view/10715 [19/05/2016].

. (1999): "La educación de la mujer según las primeras doctoras en medicina en la universidad española, año 1882”. En Dynamis, Acta Hispanica ad Medicinae Scientiarumque Historiam Ilustradam, vol. 19, pp.24-278.

- Flores, Angel y Flores, Kate (1998): Poesía feminista del mundo hispánico desde la Edad Media hasta la actualidad, México: Siglo XXI.

- Forster, Nick (2001): “A Case Study of Women Academics’ Views on Equal Opportunities, Career Prospects and Work-Family Conflicts in a UK University”. En: Career Development International, vol. $6, \mathrm{n}^{\mathrm{o}} .1$, pp. 28-38.

- Gasser, Courtney E. y Shaffer, Katharine S. (2014): "Career Development of Women in Academia: Traversing the Leakey Pipeline”. En: The Professional Counselor, vol. 4, $\mathrm{n}^{\circ}$. 4, pp. 332-352.

- Gobierno de Puerto Rico, Consejo de Educación de Puerto Rico, Área de Evaluación, Planificación, Estadísticas e investigación (2011): Informe Estadístico de las instituciones de educación superior de Puerto Rico, Años académicos 2001-02 al 2009-10. Disponible en: www.ces.gobiern ${ }^{\circ}$.pr [20/10/2015].

- Grove, Jack. (2013): Glass Ceiling Remains in Place for Female Academics, [en línea] Disponible en: https://www.timeshighereducation.com/features/global-gender-index2013/2003517.article [26/05/2016]. 
- Guil Bozal, Ana y Consuelo Flecha García (2015): "Universitarias en España: de los inicios a la actualidad". En Revista Historia de la Educación Latinoamericana, vol. 17, nº. 24, pp. 125 -148 .

- Guil Bozal, Ana (2007): "Docentes e investigadoras en las universidades españolas: visibilizando techos de cristal”. En: Revista de Investigación Educativa, vol. 25, nº. 1, pp. 1-23. - Izquierdo, Isabel (2009): “Mujeres en la academia ¿Cambio de oportunidades?”. En: Géneros, vol.2, nº. pp. 51-60.

- Jiménez Gonzáles, Carmen Leticia y Laurier, Michel (2012): "Mujeres en la administración de la educación en América Latina ¿Están todas las que son o son todas las que están?”. En: Global Conference on Business and Finance Proceeding, vol. 7, nº. 2, pp.787-792.

- Jiménez Vargas, María Constanza (n.d.): La Universidad: orígenes, avances, métodos, [en línea] Disponible en: http://virtual.udistrital.com [22/10/2015].

- Johnson, Paul (1990). Los intelectuales. Buenos Aires: Javier Vergara.

- Lagarde, Marcela (1990): Cautiverios de las mujeres: madresposas, monjas, putas, presas y locas. México: UNAM.

- Ledwith Sue y Manfredi, Simonetta (2000): "Balancing Gender in Higher Education". En: The European Journal of Women's Studies (Londres), nº.7, pp. 7-33.

- Lerner, Gerda (1993): The Creation of Feminist Consciousness, New York: Oxford University Press.

- Luzuriaga, Lorenzo (1989): Historia de la educación y la pedagogía. Buenos Aires: Losada.

- Miranda Guerrero, Roberto (2007): "Mujeres, educación superior e igualdad de género". En: CPU-e, Revista de investigación Educativa, [en línea] Disponible en: http://www.uv.mx/cpue/num4/critica/miranda_mujeres_educacion_igualdad.htm [10/10/2015]. - Manson, Mary Ann (2013): “What You Need to Know If You're an Academic and Want to be a Mom”. En: The New York Times, [en línea] Disponible en: http://www.nytimes.com/roomfordebate/2013/07/08/should-women-delay-motherhood/whatyou-need-to-know-if-youre-an-academic-and-want-to-be-a-mom [27/05/2016].

- OEI - Organización de Estados Iberoamericanos (n.d.): Declaración Final de la Conferencia Regional de Educación Superior en América Latina y El Caribe, [en línea] Disponible en: http://www.oei.es/salactsi/cres.htm [10/10/2015].

- Palermo, Alicia Itatí. (2006): "El acceso de las mujeres a los estudios universitarios (siglo XIX0". En: Tebeto, no. 19, pp.375-417.

- Ramos Tovar, María Elena (2012): “Conflicto familia-trabajo-familia y salud psicosomática entre académicos y académicas mexicanos”. En: María Elena Ramos Tovar y María Zúñiga Coronado (eds.): Voces del norte. Aportaciones regionales a los estudios de género. Monterrey: Universidad Autónoma de Nuevo León, pp. 277-301.

- Rousseau, Juan Jacobo (1989): Emilio o de la educación. México: Porrúa. 
- Sonet, Martine (1991): “La educación de una joven”. En: Duby, Georges y Michelle. Perrot. En: Historia de las mujeres. Del Renacimiento a la Edad Moderna, tomo 5, España: Taurus, pp. 130-165.

- Tomàs, Marina; Ion, Georgeta y Bernabeu, María Dolores (2013): "Ser o no ser visible en la universidad. Un estudio sobre las profesoras". En: Pedagogía Social, Revista Interuniversitaria, [en línea] Disponible en: http://dx.doi.org/10.7179/PSRI_2013.21.8 [19/11/2015].

- Woolstonecraft, Mary (1977): Vindicación de los derechos de la mujer. Madrid: Debate.

- UNESCO (2013): Oficina Regional de Educación para América Latina y el Caribe. En: Situación Educativa de América Latina y el Caribe. Hacia una educación para todos 2015, [en línea] Disponible en: http://www.unesco.org/new/fileadmin/MULTIMEDIA/FIELD/Santiago/pdf/situacioneducativa-mexico-2013.pdf [25/05/2016]. 